\title{
( 362$)$
}

XXVII. Results of the Thermometrical Observations made at Leith Fort, every Hour of the Day and Night, during the whole of the Years 1824, and 1825, By David Brewster, LL.D. F. R. S. Lond. \& Sec. R. S. Ed. Corresponding Member of the Academy of Sciences of Paris, \&c.

(Read January 23. 1826,)

$I_{N}$ the year 1820, I had occasion to suggest to the Royal Society the propriety of establishing Registers of the Thermometer in various parts of Scotland.

In a country embracing so many varieties of soil, climate and elevation, and extending over nearly six degrees of latitude, it was an object worthy of a public body to determine the Law of the Distribution of Temperature, even if such a subject had not possessed a separate interest in relation to the Horticulture and Agriculture of the Country. The Society did not hesitate in adopting this suggestion, and many intelligent individuals were found, who undertook to observe the thermometer twice a-day, and to measure occasionally the temperature of Springs and Wells, During the first year, viz. 1821, nearly sixty Meteorological Journals were regularly kept in different parts of Scotland. The number diminished considerably in subsequent years ; but, notwithstanding this diminution, there is now in our possession a rich series of observations during five complete years, the results of which are nearly ready to be submitted to the Society. 
Dr Brewster on the Register of the Thermometer. 363

In directing these observations, it became necessary to select two hours of the day most convenient for marking the state of the Thermometer, and the Mean Temperature of which approached nearest to the Mean Temperature of the day. The hours adopted were 10 o'clock A. M. and 10 P. M., which had been previously recommended by the Reverend Mr Gordon. The observations were accordingly made at these hours, during three years ; but it appeared to me, upon a more attentive consideration of the subject, that the Thermometer should be observed at the two times of the day at which the Mean Temperature occurred; for if one of the observations was omitted, the other still possessed considerable value, as an approximation to the Mean Temperature. Unfortunately, however, there were almost no observations in existence from which the times of the daily Mean Temperature could be deduced. Professor Dewey of New York had observed the Thermometer once every hour during five days at a time, in the months of March, April, $J u l y$ and October of the year 1816, and during eight days of January, and two of February in the year 1817*; and Mr Coldstream of Leith registered the Temperature of 24 successive hours once every month, from July 1822 to July 1823. From this last series of observations the Mean Temperature appeared to occur at $\frac{1}{2}$ past 7 o'clock in the morning, and $\frac{1}{2}$ past 8 in the evening; and these hours were accordingly used in most of the registers for 1824 and 1825. It was very obvious, however, that these observations, though made with great care, were too limited to afford any thing like an accurate result; and hence it became a desirable object to extend the hourly observations of the Thermometer over a greater portion of the seasons, or, if possible, to record its indications for every hour of a complete year.

- Memoirs of the American Academy of Arts and Sciences, Vol. IV. Part II. p. 392. 
364 Dn Brewsren on the Register of the Thermometer kept

As such a plan could only be carried on with effect at a military station, Leith Fort was considered the most eligible. Application was therefore made to Colonel Thackeray, commanding the Engineers, and to Colonel Younghusband and $\mathrm{Mr}$ Street of the Artillery ; and, as these gentlemen entered warmly into the scheme, preparations were made to begin the register on the 1st of January 1824. A large and accurate thermometer was constructed by Mr Anie for the purpose, and it was placed in a situation as free as possible from all disturbing causes. Its height above the level of the sea is 25 feet, and its distance from the sea 200 yards.

The register commenced on the 1st day of January 1824, and has been regularly and zealously carried on by the non-commissioned officers of the Fort for two complete years. The observations themselves are recorded in the two Folio volumes now submitted to the Society, and they may justly be regarded as possessing a high value, not only from the scientific results which they afford, but as being the only complete series of hourly observations which have been made in any part of the world *.

In reducing these observations, Mr Foggo junior of Leith computed all the hourly, monthly, and annual means for the year 1824, and Mr Christopher Bell made the same calculations for 1825. These Mean Results are given in the following Tables.

* Since this was written, we understand that similar observations, suggested by the present series, are now carrying on at Toulon and at Montreal, the last of which will possess a peculiar interest. The first example of this class of observations having been set in Scotland, we may be here allowed to express a hope, that similar hourly registers will be established by learned Societies both in Europe and America. 


\section{HOURLY REGISTER FOR 1824,}

The Mean Temperature of the Wipter months, viz. Dec. Jan. Feb. is .......... 40.67 of the Spring months, viz. March, April May, 45.38 of the Summer months, viz. June, July, Aug. 57.24 of the Autumn months, viz. Sept. Oct. Nor. 47.91

The Mean Temperature of the Year 1824, from 8784 observations, is.......... 47.81

TABLE I.-Containing the Daily and Monthly Mbax Temporatukes for 1894.

\begin{tabular}{|c|c|c|c|c|c|c|c|c|c|c|c|c|}
\hline Day. & January & Feb. & March. & pril. & May: & June. & July. & A48: & Sept & Qct. & Apu. & ec. \\
\hline 1 & 65 & 42.69 & .19 & 49 & 5.00 & 57.18 & .85 & 57.00 & 68.80 & 56.00 & 44.58 & $82.0^{\circ}$ \\
\hline 2 & & 6.69 & .72 & & & & & 56.86 & 8.69 & 51.15 & & 2.34 \\
\hline 3 & & 42.52 & 77 & 8 & 0. & & $\dot{\boldsymbol{b}}$ & 57.05 & 68.78 & 58.85 & & 0.92 \\
\hline 4 & 4 & .82 & 35.95 & 39.50 & 47.80 & 56.80 & 57.97 & & 60.86 & 58.78 & & \\
\hline 5 & & & 38.34 & 48.62 & 49.84 & 56.07 & 55.44 & 55.89 & 56.69 & 51.42 & 85.87 & 2 \\
\hline & & 40.03 & 44.52 & 44.39 & 46.81 & 52.63 & 58.29 & 55.70 & 54.10 & 52.90 & 85.63 & 38.54 \\
\hline & 3 & 49.63 & 43.29 & 45.06 & 50.67 & 60.98 & 58.75 & 57.88 & 58.18 & 53.79 & 49.80 & 38.39 \\
\hline & 4 & 46.40 & $|38.83|$ & 44.58 & 51.98 & 55.83 & 6 & 61.37 & 50.00 & 54.09 & 76 & 35.3 . \\
\hline 9 & 0.08 & .80 & $|36.50|$ & 4501 & 51.23 & 53.00 & 22 & $\mathbf{5 8 . 8 8}$ & 49.96 & 42 & 4 & 35.3 \\
\hline 10 & 67 & .21 & 35.83 & 37.92 & 49.94 & 51.63 & 58.18 & 57.43 & 51.79 & 44.39 & 4 & | \\
\hline 11 & & 40.04 & |38.32 & 37.55 & 47.38 & 50.15 & 58.92 & 56.79 & 57.09 & 46.42 & 48.32 & 48.1 \\
\hline 12 & & 43.86 & 36.82 & 39.87 & 47.15 & 58.87 & 60 & 55.94 & 57.00 & 41.60 & & 50.28 \\
\hline ] & & .51 & 36.15 & 39.27 & 47.25 & 5.45 & & 56.48 & 57.29 & 39.03 & & 48.40 \\
\hline 14 & & $37 \mid$ & 3 & 30 & 25 & 8 & & 57.22 & 36 & 5 & & 48.60 \\
\hline 1 & & 11 & 44.22 & 41.42 & 47.70 & 6 & 1 & 58.78 & 39 & 34 & & 6.10 \\
\hline 1 & 87 & 58 & 46.16 & 37.88 & 48 & 37 & 58 & $56.6 \gamma$ & 60.40 & 37.44 & 30 & 38.59 \\
\hline$\pi$ & 26 & 37.65 & 46.02 & 41.68 & 51.34 & 5 & 58 & 55.58 & 01.61 & 37 & 15 & 37.79 \\
\hline & & & 48.00 & 46.35 & 47.64 & & & 54.39 & 61.78 & 22 & & 44.09 \\
\hline & & & & 51.52 & & 2 & & & 30 & 49.98 & & 49.24 \\
\hline & & 97 & & 5 & 0 & 5 & & 3 & 31 & 48 & & 36.94 \\
\hline & & 07. & 46 & 55.47 & 44.77 & 54.03 & & 53.79 & 51.06 & 49.00 & & 37.53 \\
\hline & & 01 & 38 & 52.27 & 48.09 & 55.38 & & 52.82 & 56.66 & 54.50 & 06 & 35.45 \\
\hline & & 51 & 7 & 48.90 & 52.77 & 54.09 & 63 & 56.10 & 54.44 & 53.53 & 42.64 & 34.11 \\
\hline & & 36 & & 51.46 & & 54.57 & 2 & 58.35 & 53.44 & 52.97 & 45.27 & 40.33 \\
\hline & & & & & & 56.57 & & 63 & 50.51 & 53.96 & & 46.94 \\
\hline & & & & & & & & 37. & 79 & 48.88 & & 35.99 \\
\hline & & & & & & 78 & & 69 & & 42.22 & & .39 \\
\hline & & 05 & 39.18 & 58 & & 59.45 & & 54.33 & 30 & 40.28 & 8 & 39.80 \\
\hline & 36.47 & 40.73 & 41.68 & & 49.62 & 60.49 & 61.97 & 57.62 & 41.90 & 38.80 & & 39.78 \\
\hline$a$ & 38.54 & & 37.85 & 57.90 & 55.16 & 60.69 & 55.37 & 54.23 & 55.33 & 39.17 & 34.20 & 41.18 \\
\hline & & & & & 52.46 & & 56.06 & 57.01 & & 48.87 & & 46.93 \\
\hline & & & 2 & 9 & 4 & 55.65 & 59.46 & $|56.62|$ & 4.57 & 47.23 & 41.94 & 9.0 \\
\hline
\end{tabular}




\section{Dr BREwster on the Register of the Thermometer kept}

TABLE II.-Sheroing the Mean Temperature of each Hour for each Month of 1824, and for the whole Year.

\begin{tabular}{|c|c|c|c|c|c|c|c|c|c|c|c|c|c|}
\hline Hour. & Jan. & Feb. & Mar. & April. & May. & June. & July. & Aug. & Sept. & Oct. & Nov. & Dec. & $\begin{array}{l}\text { Mean Temp, of } \\
\text { each hour for } \\
\text { the whole year. }\end{array}$ \\
\hline 1 A. & $\overline{41.19}$ & $\overline{39.9}$ & $\overline{38.3}$ & $\overline{42.63}$ & $\overline{46.56}$ & $\overline{52.6}$ & 55.4 & $\overline{53.3}$ & $\overline{52.3}$ & $\overline{46.17}$ & 40.4 & $\overline{38.69}$ & 45.62 \\
\hline & 40.8 & 40.03 & 38.3 & 41.6 & 46.03 & 52.3 & 55.2 & 53.2 & 52.1 & 46.17 & 40.4 & 88.71 & 5.40 \\
\hline & 40.8 & $39.95 \mid$ & 38.07 & 41.00 & 45.3 & 52.1 & 55.1 & 52.9 & 51.4 & $|46.07|$ & 40.5 & $|39.02|$ & 18 \\
\hline & 40.28 & 39.68 & 37.9 & $\mathbf{4 0 . 0 8}$ & 344.7 & 518 & 54.9 & 52.5 & 51.1 & 46.2 & 40.47 & 38.9 & 3 \\
\hline & 40.07 & 39.62 & 37.65 & 39.8 & 44.9 & 51.8 & 55.2 & 52.7 & 51.2 & 45.6 & 40.45 & 38.8 & 44.82 \\
\hline & 40.1 & $|39.44|$ & 37.45 & 39.9 & 45.7 & 52.7 & 55.8 & 53.3 & 51.6 & 444.8 & 40.50 & 38.9 & 45.00 \\
\hline & 40.23 & 39.27 & 37.77 & 42.2 & 46.9 & 58.1 & 56.9 & 54.5 & 52.1 & 45.3 & 40.7 & 38.8 & 45.64 \\
\hline & 40.3 & 39.02 & 38.3 & 4.3 .1 & 48.3 & 54.3 & 58.2 & 55.5 & 53.4 & 45.9 & 40.8 & 8 & .32 \\
\hline & 40.64 & 39.93 & 39.13 & 45.9 & 49.8 & 55.2 & 59.7 & 56.8 & 55.0 & 46.6 & 41.3 & & 41 \\
\hline & 41.15 & 40.74 & 39.47 & 47.3 & 51.1 & 56.2 & 60.56 & 57.9 & 55.6 & 47.5 & 42.1 & 39.3 & 8.24 \\
\hline & 41.54 & 41.35 & 41.13 & 48.2 & 52.3 & 57.3 & 61.5 & 58.7 & 56.5 & 48.5 & 43.1 & 40.4 & 49.21 \\
\hline & 42.3 & 42.22 & 42.23 & 48.9 & 53.3 & 57.8 & 63.2 & 59.5 & 57.5 & 49.3 & 43.9 & 1.0 & 0.09 \\
\hline & 42.83 & 42.7 & 42.7 & 49.3 & 54.2 & 58.0 & 63.2 & 59.8 & 58.5 & 9.9 & 44.2 & 1.2 & .45 \\
\hline & 43.15 & 42.7 & 42.8 & 49.8 & 54.7 & 58.9 & 632 & 60.0 & 58.7 & 49.9 & 44.7 & 40.9 & 50.79 \\
\hline & 43.18 & 42.67 & 42.9 & 50.1 & 54 & 59.9 & 63.5 & 60.0 & 58.8 & 49.6 & 44.7 & 40.33 & 0.89 \\
\hline & 43.00 & 42.03 & 42.6 & 49.9 & 54.7 & 59.1 & 63.6 & 60.1 & 57.8 & 4.9 .07 & 43.4 & 39.9 & 50.43 \\
\hline & 42.22 & 41.4 & 41.9 & 49.5 & 54.1 & 58.7 & 63.4 & 59.7 & 57.8 & 48.4 & 42.8 & $\mid 39.72$ & 49.97 \\
\hline & 41.98 & 40.9 & 41.07 & 49.1 & 53.2 & 57.7 & 62.6 & 59.1 & 57.0 & 47.9 & 42.4 & 39.52 & 49.38 \\
\hline & 41.7 & 40.53 & 40.2 & 47.8 & 52.4 & 56.9 & 61.7 & 58.0 & 55.8 & 47.2 & 42.1 & 39.19 & 48.64 \\
\hline & 41.35 & 40.2 & 39.6 & 46.5 & 50 & 55.7 & 60.3 & 56.8 & 55.07 & 46.73 & 31.7 & 39.00 & 47.90 \\
\hline & 41.8 & 40.2 & 39.2 & 45.3 & 49 & 54.5 & 58.9 & 55.9 & 54.3 & 46.7 & 41.3 & 39.09 & 47.17 \\
\hline & 41.26 & 40.03 & 38.8 & 44.6 & 48.9 & 53.8 & 57.6 & 55.0 & 53.7 & 46.0 & 40.8 & 39.09 & 4.6 .64 \\
\hline & 41.12 & 39.9 & 38.3 & 43.1 & 47.8 & 53.2 & 56.9 & 54.3 & 53.4 & 45.8 & 40.4 & 39.1 & 46.20 \\
\hline & 40.92 & 39. & 38.3 & 42.7 & 47.1 & 52.7 & 56.03 & 53.8 & 52.7 & 45.7 & 40.3 & 39.29 & 45.79 \\
\hline
\end{tabular}

The Mean Temperature obtained from the last column in the above Table, is $47^{\circ} .588$.

It occurred at $9^{\text {h }} 13^{\prime}$ A. M. and at $8^{\text {h }} 26^{\prime}$ P. M. 
every Hour of the Day at Leith Fort in 1824 and 1825. $\quad 367$

HOURLY REGISTER FOR 1825.

The Mean 'Temperature of the Winter months, viz. Dec. Jan. Feb. is ........ 40.312 of the Spring months, viz. March, April, May, ..... 46.121 of the Summer months, viz. June, July, Aug. ........ 59.306 of the Autumn months, viz. Sept. Oct. Nov. ........ 49.907

The Mean Temperature of the year 1825, from 8760 observations, is.......... 48.911

TABLE III.-Containing the Daily and Monthly Mean Temperatures for 1825.

\begin{tabular}{|c|c|c|c|c|c|c|c|c|c|c|c|c|}
\hline Day. & Jan. & eb. & arch. & April. & May. & June. & July. & Aug. & Sept. & Oct. & Nor. & Dec. \\
\hline $\begin{array}{r}1 \\
2 \\
3 \\
4 \\
5 \\
6 \\
7 \\
8 \\
9 \\
10 \\
11 \\
12 \\
13 \\
14 \\
15 \\
16 \\
17 \\
18 \\
19 \\
20 \\
21 \\
22 \\
23 \\
24 \\
25 \\
26 \\
27 \\
28 \\
29 \\
30 \\
31\end{array}$ & $\begin{array}{l}45.15 \\
39.83 \\
43.47 \\
37.35 \\
30.32 \\
39.26 \\
44.17 \\
39.80 \\
38.11 \\
35.55 \\
41.48 \\
39.91 \\
42.03 \\
44.75 \\
46.73 \\
43.99 \\
39.38 \\
41.22 \\
39.15 \\
40.09 \\
39.30 \\
37.02 \\
36.33 \\
38.03 \\
34.45 \\
41.30 \\
47.65 \\
38.83 \\
48.88 \\
47.62 \\
42.93\end{array}$ & $\begin{array}{l}41.31 \\
41.81 \\
32.99 \\
28.72 \\
38.08 \\
34.99 \\
38.51 \\
38.81 \\
42.78 \\
47.11 \\
46.28 \\
46.06 \\
46.98 \\
41.82 \\
41.48 \\
41.79 \\
433.52 \\
41.26 \\
41.78 \\
43.73 \\
40.91 \\
42.63 \\
40.88 \\
40.17 \\
39.08 \\
37.69 \\
38.61 \\
36.75\end{array}$ & \begin{tabular}{|l}
39.78 \\
37.29 \\
36.13 \\
36.20 \\
36.50 \\
38.24 \\
39.55 \\
44.20 \\
52.46 \\
52.48 \\
44.97 \\
44.18 \\
43.41 \\
37.83 \\
36.40 \\
36.04 \\
36.75 \\
39.07 \\
43.31 \\
40.58 \\
39.78 \\
42.55 \\
40.61 \\
38.12 \\
42.03 \\
42.81 \\
48.70 \\
45.39 \\
47.47 \\
44.78 \\
42.29
\end{tabular} & $\begin{array}{l}42.38 \\
45.89 \\
47.46 \\
49.74 \\
54.18 \\
47.26 \\
49.80 \\
52.11 \\
47.04 \\
48.55 \\
50.13 \\
41.03 \\
40.79 \\
48.62 \\
52.50 \\
50.49 \\
45.06 \\
40.54 \\
42.30 \\
50.49 \\
53.04 \\
46.81 \\
42.76 \\
42.37 \\
42.80 \\
45.28 \\
45.88 \\
47.35 \\
47.88 \\
48.51\end{array}$ & $\begin{array}{l}44.71 \\
46.09 \\
49.14 \\
52.73 \\
48.69 \\
52.59 \\
53.19 \\
54.63 \\
54.27 \\
50.77 \\
48.32 \\
48.75 \\
417.50 \\
48.91 \\
49.74 \\
49.05 \\
51.95 \\
53.55 \\
53.41 \\
50.41 \\
49.01 \\
52.14 \\
50.48 \\
46.01 \\
45.60 \\
48.55 \\
47.02 \\
45.18 \\
47.96 \\
50.17 \\
52.74\end{array}$ & \begin{tabular}{|l}
56.88 \\
58.41 \\
53.61 \\
50.52 \\
499.43 \\
52.35 \\
58.30 \\
57.46 \\
55.24 \\
59.59 \\
65.67 \\
62.71 \\
59.09 \\
60.14 \\
58.85 \\
68.52 \\
60.51 \\
58.45 \\
52.46 \\
52.70 \\
52.09 \\
53.16 \\
57.68 \\
57.59 \\
57.14 \\
52.44 \\
54.35 \\
54.70 \\
55.95 \\
55.05
\end{tabular} & $\begin{array}{l}55.50 \\
57.81 \\
58.54 \\
59.56 \\
58.66 \\
59.24 \\
58.09 \\
57.05 \\
56.05 \\
55.25 \\
56.26 \\
61.09 \\
65.45 \\
69.94 \\
65.51 \\
66.77 \\
69.63 \\
66.63 \\
62.29 \\
60.02 \\
59.07 \\
59.83 \\
56.63 \\
57.10 \\
63.29 \\
61.01 \\
64.94 \\
60.22 \\
61.05 \\
68.53 \\
68.20\end{array}$ & $\begin{array}{l}63.77 \\
63.56 \\
63.27 \\
59.60 \\
59.71 \\
58.21 \\
59.06 \\
59.88 \\
57.71 \\
59.37 \\
57.34 \\
56.41 \\
59.74 \\
56.78 \\
57.91 \\
56.88 \\
57.17 \\
59.01 \\
59.07 \\
65.40 \\
64.35 \\
60.41 \\
65.44 \\
57.88 \\
58.04 \\
57.23 \\
58.45 \\
59.21 \\
61.92 \\
65.35 \\
65.72\end{array}$ & \begin{tabular}{|l}
60.40 \\
59.19 \\
59.30 \\
57.07 \\
55.39 \\
55.99 \\
58.79 \\
55.45 \\
58.30 \\
60.26 \\
58.21 \\
60.55 \\
56.27 \\
56.30 \\
56.79 \\
61.21 \\
62.40 \\
62.59 \\
60.95 \\
59.87 \\
60.34 \\
54.95 \\
49.44 \\
63.49 \\
62.16 \\
56.29 \\
56.59 \\
59.00 \\
55.45 \\
54.66
\end{tabular} & $\begin{array}{l}53.69 \\
60.36 \\
60.03 \\
58.81 \\
58.38 \\
57.57 \\
53.79 \\
54.48 \\
55.49 \\
56.79 \\
54.00 \\
57.80 \\
54.09 \\
58.57 \\
52.51 \\
54.65 \\
47.16 \\
46.75 \\
46.23 \\
40.24 \\
41.47 \\
42.47 \\
51.07 \\
448.97 \\
40.65 \\
39.26 \\
45.58 \\
52.41 \\
50.98 \\
51.90 \\
46.81\end{array}$ & $\begin{array}{l}46.35 \\
42.08 \\
42.53 \\
40.36 \\
43.04 \\
41.52 \\
36.04 \\
36.82 \\
35.73 \\
32.37 \\
36.22 \\
33.78 \\
42.32 \\
40.82 \\
36.49 \\
44.19 \\
44.61 \\
45.56 \\
41.14 \\
45.56 \\
45.22 \\
40.76 \\
44.74 \\
43.30 \\
40.43 \\
44.80 \\
35.81 \\
36.44 \\
39.84 \\
34.63\end{array}$ & $\begin{array}{l}33.79 \\
36.85 \\
34.59 \\
37.84 \\
37.09 \\
40.72 \\
43.21 \\
44.71 \\
42.95 \\
43.35 \\
44.12 \\
43.90 \\
42.45 \\
38.56 \\
41.06 \\
46.04 \\
45.40 \\
47.05 \\
42.66 \\
42.44 \\
45.92 \\
40.02 \\
40.22 \\
39.75 \\
43.85 \\
35.14 \\
33.00 \\
35.86 \\
35.01 \\
32.81 \\
28.58\end{array}$ \\
\hline $\left.\begin{array}{l}\text { emp. } \\
\text { f each } \\
\text { nonth, }\end{array}\right\}$ & 583 & $41 \%$ & 610 & 968 & 785 & .531 & .262 & 30.125 & 3.055 & 51.223 & 0.443 & $\begin{array}{l}9.940 \\
0\end{array}$ \\
\hline
\end{tabular}


368 DR BREwster on the Register of the Thermometer kept

TABLE IV.-Shewing the Mean Temperature of each Hour for each Month in 1825, and for the whole Year.

\begin{tabular}{|c|c|c|c|c|c|c|c|c|c|c|c|c|c|}
\hline Hour. & Jan. & Feb. & March. & April. & May. & June. & July. & ug. & Sept. & Oct. & Nor & Dec. & $\begin{array}{l}\text { Mean Temp of } \\
\text { each hour for } \\
\text { the whole year. }\end{array}$ \\
\hline & & & & 50 & & 5 & 35 & 7.355 & 55.358 & .984 & 9.325 & 3.19 & 46. \\
\hline & & & & & & & & & & & & & \\
\hline 3 & & & & & & & & & & & & & \\
\hline & 39. & & & & & & & & & & & & 969 \\
\hline 5 & 39.814 & & & 317 & & & & ת & & 516 & 39.050 & & 45.968 \\
\hline 6 & 39.774 & & & & & & & & & 84 & 39.183 & 39.234 & 16.307 \\
\hline 7. & & & & & & & & & & & & & 927 \\
\hline 8 & & & & & & & & & & & & & \\
\hline 9 & & & & & & & & & & & & & \\
\hline & & & & & & & & & & & & & \\
\hline & 41 & & & & & & & & & 258 & & 40. & 91 \\
\hline 10 & & & & & & & & & & & & & 164 \\
\hline & & & & & & & & & & & & & 48 \\
\hline & & & & & & & & & & & & & 50 \\
\hline & & & & & & & & & & & & & 74 \\
\hline & & & & & & & & & & & & & 49 \\
\hline & & & & & & & & & & & 41.517 & 40.652 & 774 \\
\hline & & & & & & & & & & & 41.192 & & \\
\hline & & & & & & & & & & & & & \\
\hline & & & & & & & & & & & & & \\
\hline & & & & & & & & & & & & & \\
\hline & & & & & & & & & & & & & \\
\hline & 40 & 39 & 40. & & & & & & & & & & 07 \\
\hline & 40.339 & 39.1 & 40.24 .2 & 44.1 & 47.92 & 53675 & 57. & & 55 & $49.670 \mid$ & & & $47.00^{\prime}$ \\
\hline
\end{tabular}

The Mean Temperature obtained from the last column of the above Table is $48^{\circ} .944$. It occurred at $9^{\text {h }} 13^{\prime}$ A. M. and $8^{\text {h }} 28$ P. M. 
MFAN RESULTS OF THE HOURLY REGISTER FOR 1824 AND 1825.

The Mean Temperature of the Winter months, viz. Dec. Jan. Feb. is 40.491 of the Spring months, viz. March, April, May 45.751 of the Summer months, viz. June, July, Aug. 58.273 of the Autumn months, viz. Sept. Oct. Nov .48 .908

The Mean Temperature of the years 1824 and 1825, from 17,544 observations, is......48.360

TABLE V.-Containing the Average of the Daily and Monthly Temperatures of the Years 1824 and 1825.

\begin{tabular}{|c|c|c|c|c|c|c|c|c|c|c|c|c|}
\hline Day. & January. & Feb. & March. & April. & May. & June. & July. & August. & Sept. & October. & Nov. & ? \\
\hline $\begin{array}{r}1 \\
2 \\
3 \\
4 \\
.5 \\
6 \\
7 \\
8 \\
9 \\
10 \\
11 \\
12 \\
13 \\
14 \\
15 \\
16 \\
17 \\
18 \\
19 \\
20 \\
21 \\
22 \\
23 \\
24 \\
25 \\
26 \\
27 \\
28 \\
29 \\
30 \\
31\end{array}$ & \begin{tabular}{|l}
43.85 \\
41.67 \\
41.47 \\
40.57 \\
37.35 \\
39.97 \\
40.33 \\
42.55 \\
44.09 \\
40.61 \\
40.69 \\
41.61 \\
42.15 \\
42.02 \\
39.57 \\
38.68 \\
38.82 \\
42.61 \\
39.85 \\
44.01 \\
39.31 \\
38.16 \\
37.46 \\
39.17 \\
41.24 \\
46.44 \\
45.62 \\
38.76 \\
40.18 \\
43.08 \\
44.06
\end{tabular} & \begin{tabular}{|l}
42.00 \\
42.25 \\
37.75 \\
34.77 \\
35.88 \\
37.51 \\
44.07 \\
44.61 \\
42.27 \\
45.16 \\
43.16 \\
44.71 \\
43.24 \\
40.59 \\
38.19 \\
39.16 \\
40.58 \\
39.66 \\
41.54 \\
42.40 \\
40.99 \\
42.32 \\
41.19 \\
40.76 \\
39.90 \\
37.76 \\
38.40 \\
38.40
\end{tabular} & $\begin{array}{l}37.48 \\
35.01 \\
34.05 \\
35.72 \\
37.42 \\
44.38 \\
41.42 \\
41.52 \\
44.48 \\
44.15 \\
41.64 \\
40.50 \\
39.78 \\
38.12 \\
40.31 \\
41.10 \\
41.38 \\
43.53 \\
44.18 \\
45.30 \\
42.56 \\
40.75 \\
39.64 \\
39.74 \\
42.16 \\
41.98 \\
44.34 \\
42.28 \\
44.57 \\
41.31 \\
38.07\end{array}$ & \begin{tabular}{|l}
37.93 \\
42.62 \\
42.49 \\
44.62 \\
48.90 \\
45.79 \\
47.43 \\
48.34 \\
46.03 \\
43.23 \\
43.84 \\
40.45 \\
40.03 \\
44.61 \\
46.96 \\
44.19 \\
43.37 \\
43.45 \\
46.91 \\
52.71 \\
54.25 \\
49.54 \\
45.83 \\
46.92 \\
47.72 \\
49.61 \\
48.45 \\
50.46 \\
51.52 \\
53.20
\end{tabular} & \begin{tabular}{|l}
49.85 \\
49.17 \\
48.07 \\
50.26 \\
49.26 \\
49.70 \\
51.93 \\
53.30 \\
52.75 \\
50.35 \\
47.85 \\
47.95 \\
47.37 \\
47.08 \\
48.72 \\
48.60 \\
51.64 \\
50.59 \\
48.52 \\
46.45 \\
46.81 \\
50.11 \\
51.62 \\
50.27 \\
51.39 \\
52.65 \\
53.39 \\
50.73 \\
48.79 \\
52.66 \\
52.60
\end{tabular} & \begin{tabular}{|l}
$\mathbf{5 7 . 0 0}$ \\
$\mathbf{5 6 . 7 5}$ \\
$\mathbf{5 6 . 1 2}$ \\
$\mathbf{5 3 . 6 6}$ \\
$\mathbf{5 2 . 7 5}$ \\
$\mathbf{5 2 . 4 9}$ \\
$\mathbf{5 9 . 6 4}$ \\
$\mathbf{5 6 . 6 4}$ \\
$\mathbf{5 4 . 1 2}$ \\
$\mathbf{5 5 . 6 1}$ \\
$\mathbf{5 7 . 9 1}$ \\
$\mathbf{5 8 . 2 9}$ \\
$\mathbf{5 7 . 2 7}$ \\
$\mathbf{5 5 . 9 6}$ \\
$\mathbf{5 0 . 3 5}$ \\
$\mathbf{5 8 . 4 4}$ \\
$\mathbf{5 6 . 2 6}$ \\
$\mathbf{5 6 . 4 5}$ \\
$\mathbf{5 2 . 7 9}$ \\
$\mathbf{5 2 . 7 8}$ \\
$\mathbf{5 3 . 0 6}$ \\
$\mathbf{5 4 . 2 7}$ \\
$\mathbf{5 5 . 8 8}$ \\
$\mathbf{5 6 . 0 6}$ \\
$\mathbf{5 6 . 8 5}$ \\
$\mathbf{5 5 . 0 9}$ \\
$\mathbf{5 6 . 5 6}$ \\
$\mathbf{5 7 . 0 7}$ \\
$\mathbf{5 8 . 2 2}$ \\
$\mathbf{5 7 . 8 7}$
\end{tabular} & \begin{tabular}{|l}
55.67 \\
57.86 \\
57.23 \\
58.76 \\
57.05 \\
58.76 \\
58.42 \\
60.35 \\
59.13 \\
56.71 \\
57.59 \\
60.68 \\
61.60 \\
68.09 \\
65.01 \\
62.79 \\
63.99 \\
61.93 \\
60.18 \\
60.65 \\
60.03 \\
62.78 \\
59.99 \\
57.01 \\
61.01 \\
60.02 \\
61.82 \\
60.37 \\
61.51 \\
61.95 \\
62.13
\end{tabular} & \begin{tabular}{|l}
$\mathbf{6 0 . 3 8}$ \\
$\mathbf{6 0 . 2 1}$ \\
$\mathbf{6 0 . 1 6}$ \\
$\mathbf{5 8 . 5 7}$ \\
$\mathbf{5 7 . 8 0}$ \\
$\mathbf{5 6 . 9 5}$ \\
$\mathbf{5 8 . 2 2}$ \\
$\mathbf{6 0 . 6 2}$ \\
$\mathbf{5 8 . 2 9}$ \\
$\mathbf{5 8 . 4 0}$ \\
$\mathbf{5 7 . 0 7}$ \\
$\mathbf{5 6 . 1 7}$ \\
$\mathbf{5 8 . 1 1}$ \\
$\mathbf{5 7 . 0 0}$ \\
$\mathbf{5 8 . 3 2}$ \\
$\mathbf{5 6 . 7 7}$ \\
$\mathbf{5 6 . 3 7}$ \\
$\mathbf{5 6 . 7 0}$ \\
$\mathbf{5 8 . 0 7}$ \\
$\mathbf{6 0 . 7 2}$ \\
$\mathbf{5 9 . 0 7}$ \\
$\mathbf{5 6 . 6 1}$ \\
$\mathbf{6 0 . 7 7}$ \\
$\mathbf{5 8 . 1 1}$ \\
$\mathbf{5 7 . 3 3}$ \\
$\mathbf{5 6 . 9 5}$ \\
$\mathbf{5 7 . 0 7}$ \\
$\mathbf{5 6 . 7 7}$ \\
$\mathbf{5 9 . 7 7}$ \\
$\mathbf{5 9 . 7 9}$ \\
$\mathbf{6 1 . 3 6}$
\end{tabular} & \begin{tabular}{|l}
61.60 \\
63.44 \\
63.54 \\
58.71 \\
56.04 \\
55.04 \\
56.48 \\
52.72 \\
54.13 \\
56.02 \\
57.65 \\
58.77 \\
56.78 \\
57.83 \\
57.59 \\
66.80 \\
62.01 \\
62.18 \\
57.62 \\
55.84 \\
55.70 \\
55.81 \\
51.94 \\
58.46 \\
56.33 \\
49.54 \\
48.14 \\
46.65 \\
48.67 \\
54.99
\end{tabular} & \begin{tabular}{|l}
54.82 \\
55.75 \\
56.64 \\
55.76 \\
54.90 \\
55.23 \\
58.79 \\
54.29 \\
51.95 \\
50.59 \\
50.21 \\
49.70 \\
46.56 \\
48.86 \\
45.42 \\
46.94 \\
42.36 \\
45.48 \\
48.10 \\
44.36 \\
45.23 \\
48.48 \\
52.30 \\
50.97 \\
47.30 \\
44.07 \\
43.90 \\
46.34 \\
44.89 \\
45.53 \\
47.84
\end{tabular} & \begin{tabular}{|l}
45.44 \\
43.44 \\
41.18 \\
38.34 \\
39.45 \\
38.58 \\
42.67 \\
41.29 \\
40.24 \\
39.15 \\
39.77 \\
36.62 \\
45.66 \\
42.02 \\
36.13 \\
45.01 \\
48.38 \\
44.02 \\
41.13 \\
43.54 \\
43.30 \\
40.41 \\
43.69 \\
44.28 \\
41.05 \\
41.96 \\
36.12 \\
38.46 \\
39.94 \\
34.42
\end{tabular} & \begin{tabular}{|l}
32.93 \\
34.59 \\
32.75 \\
32.97 \\
$\mathbf{8 2 . 9 6}$ \\
$\mathbf{3 9 . 6 3}$ \\
40.80 \\
40.05 \\
39.17 \\
39.07 \\
46.13 \\
47.09 \\
45.42 \\
43.58 \\
43.58 \\
42.31 \\
41.59 \\
45.57 \\
45.95 \\
39.69 \\
41.72 \\
37.73 \\
37.16 \\
40.04 \\
45.39 \\
35.56 \\
38.69 \\
37.83 \\
37.39 \\
36.99 \\
37.75
\end{tabular} \\
\hline Means, & 41.091 & 40.621 & 40.865 & 6.379 & 0.012 & 56.091 & 60.361 & 58.372 & 56.312 & 49.226 & 41.191 & 39.775 \\
\hline
\end{tabular}


TABLE VI.-Shewing the Average Mean Temperature of each Hour for each Month in 1824, and 1825, and the average of these Two Years.

\begin{tabular}{|c|c|c|c|c|c|c|c|c|c|c|c|c|c|}
\hline Hour. & Jan. & Feb. & March. & April. & May. & June. & July. & Aug. & Sept. & Oct. & Nov. & Dec. & $\begin{array}{l}\text { Mean Temp. of } \\
\text { each hour for the } \\
\text { whole two years. }\end{array}$ \\
\hline & 40.131 & 39.668 & 38.952 & 42.990 & .100 & 52.587 & 56.167 & 55.327 & 53.829 & 48.077 & 39.862 & 38.942 & 46.134 \\
\hline & 40.384 & 39.751 & 38.731 & 42.171 & 46.390 & 52.250 & 55.999 & 55.068 & 53.579 & 47.976 & 39.600 & 39.020 & 45.933 \\
\hline 3 & 40.311 & 39.774 & 38.293 & 41.525 & 45.880 & 52.116 & 55.593 & $\mathbf{5 4 . 7 8 0}$ & 53.096 & 47.877 & 39.737 & 39.062 & 45.689 \\
\hline 4 & 40.067 & 39.594 & 38.127 & 40.794 & 45.430 & 51.887 & 55.152 & 54.564 & 52.716 & 47.8 & 39.664 & 38.966 & 45.449 \\
\hline 5 & 39.942 & $\mid 39.354$ & 37.962 & 40.558 & 45.550 & 51.933 & 55.660 & 54.632 & 52.596 & 47.558 & 39.750 & 38.908 & 45.394 \\
\hline 6 & 39.932 & 39.229 & 37.927 & 40.721 & 46.322 & 52.829 & 56.718 & 55.029 & 52.858 & 47.142 & & 39.062 & 653 \\
\hline 7 & 40.030 & 39.295 & 38.244 & 42.625 & 47.188 & 53.625 & 57.877 & 56.021 & 53.646 & 47.548 & 40.058 & 38.997 & 46.283 \\
\hline 8 & 40.113 & $|39.269|$ & $38.912 \mid$ & 43.912 & 48.449 & $\mathbf{5 4 . 7 7 5}$ & 59.1 & 57.19 & 54.921 & 48.175 & 40.092 & 39.134 & 47.029 \\
\hline 9 & 40.381 & 39.759 & $39.895 \mid$ & 46.371 & 49.726 & 56.041 & 60.499 & 58.380 & 56.525 & 48.868 & 40.562 & 39.359 & 48.055 \\
\hline 10 & 40.829 & 40.606 & 40.537 & 48.096 & 50.901 & 57.158 & 61.626 & 50 & 70 & 49.992 & 41.462 & 39.694 & 49.012 \\
\hline 11 & 41.350 & 41.510 & 42.915 & 49.096 & 51.830 & 58 & 62.500 & 60.297 & a & 50.879 & 42.466 & 40.522 & 49.950 \\
\hline 18 & 42.024 & 42.230 & 43.317 & 50.021 & 52.581 & 58.654 & 63.842 & 61.254 & 59. & 51.533 & 43.079 & 41.008 & \\
\hline & 42.415 & $\mid 42.774$ & 43.680 & 50.458 & 53.193 & 59.025 & 63.935 & 61.714 & 60.300 & 51.954 & 43.433 & 41.184 & 51.149 \\
\hline & 42.59 & 42.761 & 44.013 & 50.808 & 53.620 & 59 & & & 60.637 & $\mid 52.018$ & 43.704 & 41.216 & 51.470 \\
\hline 3 & 42.594 & 42.799 & 44.079 & 51.187 & 53.693 & 60.216 & 64.649 & 61.915 & 60. & 51. & 43.754 & 40.790 & 32 \\
\hline 4 & 42.185 & 42.256 & 44.042 & 50.879 & 54.007 & 59.808 & 64.703 & 62.155 & 59.937 & 51.132 & 42.825 & 40.502 & 51.239 \\
\hline 5 & 41.686 & 41.481 & 43.555 & 50.337 & 53.872 & 59.575 & 64.825 & 62.043 & 59.921 & 50.478 & 42.158 & 40.186 & 0872 \\
\hline 6 & 41.450 & 40.994 & 42.850 & 49.933 & 53.346 & 59.145 & 64.671 & 61.743 & 58.666 & $|49.756|$ & 41.796 & $|39.937|$ & 50.294 \\
\hline 7 & 41.082 & 40.617 & 41.878 & 48.537 & 52.442 & 58.383 & 63.837 & 59.963 & 57.337 & 49.132 & 41.383 & & \\
\hline 8 & 40.877 & 40.225 & 41.155 & 46.900 & 51.019 & 56.654 & 61.553 & 58.694 & 56.539 & 48.603 & 41.071 & 39.379 & 24 \\
\hline 9 & 40.792 & & 40.459 & 45.708 & 49.5 & $|55.371|$ & 59.821 & 57.6 & $|55.791|$ & 48.451 & 40.825 & 39.311 & 47.829 \\
\hline 10 & 40.827 & 39. & 39.941 & 45.0 & 48.9 ? & 54.483 & 58.546 & 56.704 & 55.137 & 48.064 & 40.333 & 39.250 & 47.276 \\
\hline & 40.70 & & 39.411 & 43.9 & 48.1 & 53.712 & 57.740 & 56.039 & $54.72 \mathrm{i}$ & 47.771 & 39.941 & 39.126 & 46.803 \\
\hline 12 & & & 39.271 & 19416 & 1751 & 53.187 & 5691 & 55 & & & 39.708 & 39.072 & 46.398 \\
\hline
\end{tabular}

The Mean Temperature obtained from the last columns of the preceding Table is $48^{\circ} .266$. It occurred at $9^{\text {h }} 13^{\prime}$ A. M. and $8^{\text {h }} 27^{\prime}$ P. M. 
every Hour of the Day at Leith Fort in 1824 and 1825. 371

Having given, in the preceding Tables, all the numerical results of the hourly Register for 1824 and 1825, I shall now proceed to consider some of the most important conclusions which may be deduced from them. 'These relate,

1. To the form and character of the annual and monthly daily curve, or the daily progression of temperature.

2. To the determination of the two times of the day when the mean temperature occurs.

3. To the relation between the mean temperature of the 24 hours, and that of any single hour, or pair of similar hours, \&c.

4. To the average daily range for each month.

5. To the Parabolic form of the branches of the Annual Daily Curve.

1. On the Form and Character of the Annual and Monthly Daily Curve, or the Daily Progression of Temperature.

The daily curve for 1824 is projected in Plate XIV., from the numbers in the last column of Table II., and forms the lowest curve. The point of the curve for each of the 24 hours is the mean of 366 observations. The temperature is lowest between 4 and 5 o'clock in the morning; it then increases with great regularity till three o'clock in the afternoon, when it descends till it reaches its minimum at 5 o'clock in the morning. 'The period during which it performs its ascending motion is $9^{\mathrm{h}} 40^{\prime}$, and the period of its descending motion is $14^{\mathrm{h}} 20^{\prime}$; the heat of the day, therefore, advances with more rapidity than the cold of the night.

The daily curve of 1825 is projected in a similar manner in Plate XIV. from the first column of Table IV., and forms the 
upper curve of the Plate. Each point of it is the mean of 365 observations. Its resemblance and general parallelism to that of 1824, cannot fail to strike the reader, and proves how nearly these observations have conducted us to the form of the daily curve.

The intermediate curve, which is laid down from the last column of Table VI., and is the mean of the two curves, is nearly free from the very slight inequalities in the afternoon branch of both curves, and may be considered as representing with great accuracy the mean annual daily curve for the Latitude of Leith, and at the level of the sea.

In order to observe the variation in the form of the daily curves for different seasons, I have given in Plate XV: and XVI. their projections for every month in 1824 and 1825; and in Plate XVII. the mean of the monthly curves in 1824 and 1825. These curves obviously divide themselves into three groupes or classes, viz. 1. 'The Curves of High Temperature, such as those of June, July, August and September; 2. The Curves of Low Temperature, such as those of November, December, January, February, March; and, 3. The Curves of Moderate Temperature, such as those of April, May, and October.

But though the curves thus group themselves into three varieties of temperature, yet it is obvious that those of April and May have the same form as those of the summer months, while the curve of October resembles the flat curves of the winter months. In order, therefore, to obtain a type of the daily curves of summer and winter, I have joined October to the winter months, and April and May to the summer ones, as in the following Table for 1824 and 1825*.

* It is probable that the Royal Society of Edinburgh will publish a series of Plates representing the daily curve for each day of 1824 and 1825. 
at Leith Fort every Hour of the Day in 1824 and 1825. 373

$T A B L E$, shewing the Mean Temperature of each Hour for Six Summer Months, from April to September inclusive, and for Six Winter Months from October to March inclusive.

$\begin{array}{rcc}\text { Hours. } & \text { Six Summer Months. } & \text { Six Winter Months. } \\ 1 \text { A.M. } & 51.27 & 40.77 \\ 2 & 50.90 & 40.91 \\ 3 & 50.50 & 40.84 \\ 4 & 50.09 & 40.70 \\ 5 & 50.15 & 40.57 \\ 6 & 50.77 & 40.52 \\ 7 & 51.83 & 40.69 \\ 8 & 53.06 & 40.94 \\ 9 & 54.59 & 41.46 \\ 10 & 55.80 & 42.19 \\ 11 & 56.74 & 43.27 \\ 12 & 57.64 & 43.86 \\ 1 \text { P.M. } & 58.10 & 44.24 \\ 2 & 58.50 & 44.38 \\ 3 & 58.70 & 44.29 \\ 4 & 58.58 & 43.83 \\ 5 & 58.43 & 43.26 \\ 6 & 57.92 & 42.80 \\ 7 & 56.75 & 42.26 \\ 8 & 55.22 & 41.88 \\ 9 & 53.98 & 41.62 \\ 10 & 53.15 & 41.34 \\ 11 & 52.38 & 41.08 \\ 12 & 51.91 & 40.97 \\ & 54.59 & 40.68 \\ & 54 & \end{array}$

By means of this Table I have projected the summer and winter curves, as in Plate XVIII. These curves are beautifully regular, and may be regarded as an accurate type of the daily progression of temperature in summer and winter, each point of each curve being the mean of about 180 observations. 
374. Dr BRewster on the Register of the Thermometer kept

The summer curve descends regularly from midnight till 4 o'clock in the morning, when the coldest time of the day occurs, and it ascends with great regularity till 3 o'clock, when it commences a very rapid descent to its minimum; the total mean range being about $8^{\circ} .61$.

The winter curve, on the contrary, has a gentle rise from 1 A. м. till 2 A. M. It then descends till 6 , when it commences its ascent, reaches its maximum at 2 , and again descends, but more slowly than it rose, the greatest difference of temperature being about $3^{\circ} .86$. By examining the individual curves which compose the winter group, especially in the means of 1824 and 1825, the rise of temperature after midnight, and its subsequent fall, will be very apparent,-an effect which never takes place in the curves of summer.

The difference of character in the curves of April and October deserves to be noticed. Although these months are considered as giving nearly the mean of the year, and therefore as resembling each other in temperature, yet there is a singular difference in the mode of its distribution. In October the mornings and evenings are comparatively warm, while in April these times of the day are remarkably cold. April, in short, unites the low temperature of a winter month, with the great range of a summer month; while October unites the temperature of a summer month, with the low range of a winter one.

II. On the Determination of the two times of the Day, when the Mean Temperature occurs.

I am not aware of any observations made in our climate, by which the hours, when the mean temperature of the day occurs, could be determined. It has generally been believed that it occurs at 8 o'clock in the morning; and Professor Playfair not 
at Leith Fort every Hour of the Day in 1824 and 1825. 375

only considers this as nearly the hour of mean temperature for Edinburgh, but he regards the maximum as occurring "from 1 to half past 2, or even 3 o'clock*;" and upon these principles he has selected his three hours, viz. 8 A. M., the time of maximum, and 10 o'clock P. $\mathrm{M}$.

It appears, however, from Tables II., IV. and VI. that the mean temperature of the 24 hours occurs at the following times :

$\begin{array}{ccc} & \begin{array}{c}\text { Hours of Morning } \\ \text { Mean Temperature. }\end{array} & \begin{array}{c}\text { Hours of Evening } \\ \text { Mean Temperature. }\end{array} \\ \text { 1824, } & \mathbf{9} 13^{\prime} & \text { H. } 26^{\prime} \\ 1825, & 913 & 828 \\ \text { Mean of two years, } & \mathbf{9 1 3} & \underline{827}\end{array}$

This very extraordinary agreement between the results of 1824 and 1825, shews how nearly we have approximated to the true form of the daily curve, and how much confidence may be placed in the general result. The following may therefore be regarded as the leading points of the annual daily curve.

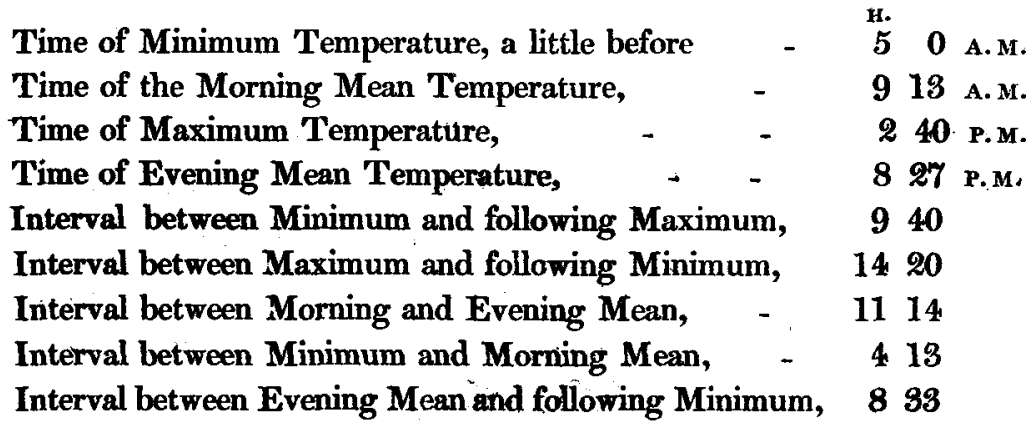

* Edinburgh Transactions, vol. iv. p. 214, and vol. v. p. 293, 294. Mr PraxFAIr also adds, that 10 o'clock $P . M$. is " as near as circumstances will allow to the time of greatest cold." These opinions prove how little was then known of the form of the daily curve. It will be seen from Plate XVIII. that, both in the winter and the summer curve, the maximum temperature is never before 3 o'clock, and that 10 o'clock at night is nearer the mean than the minimum temperature of the day.

VoL. X. P. II. 
The determination of the exact times of mean temperature throughout the year, furnishes us with the two best times of the day for recording the indications of the thermometer. These times at Leith are obviously $9^{\mathrm{h}} 13^{\prime}$ A. M. and $8^{\mathrm{h}} 27^{\prime}$ P. M. ; for, if any of the observations is accidentally omitted at one of the hours, the mean of the remainder will approach nearer to the mean temperature of the year, than if any other two hours had been taken, and similar omissions made.

There is, however, another advantage of this determination, namely, that the mean temperature of the year may be obtained with great accuracy by a single observation made every day at one of the times of mean temperature. Let us suppose that we wished to determine the mean temperature of the year 1825 at Leith, and that we had possessed no other observations than a single daily one made at $9^{\mathrm{h}} 13^{\prime}$, then the mean of these 365 daily ones would have been $48^{\circ} .944$, the very same result that has been obtained in 1825 from 24 observations every day.

If we examine the annual curve, and also the monthly curve, it will be seen, that the ascending or morning branch is more regular in its progression than the descending or evening branch. On this account, we would prefer a single observation every day, made at the time of the morning mean, to a single observation made every day at the time of the evening mean.

It must be carefully observed, that the hours of mean temperature which we have now been considering, are only mean results for the whole year. If we wished to deduce the mean monthly temperatures from an observation made once a-day, it would not answer to take $9^{\mathrm{h}} 13^{\prime}$ A. M. and $8^{\mathrm{h}} 27^{\prime}$ P. M.; ; 90 the times of mean monthly temperature occur at different hours of the day throughout the year, as will appear from the following Table : 
at Leith Fort every Hour of the Day in 1824 and 1825. 377

TABLE, shewing the Hours of the Morning and Evening when the Mean Monthly Temperature occurs.

\begin{tabular}{|c|c|c|c|c|c|c|}
\hline \multirow[b]{2}{*}{ January, } & \multicolumn{2}{|c|}{1824.} & \multicolumn{2}{|c|}{1825.} & \multicolumn{2}{|c|}{$\begin{array}{c}\text { Mean of } \\
\text { 1824 \& 1825. }\end{array}$} \\
\hline & $\begin{array}{l}\text { A. M. } \\
\text { 11 } \\
11\end{array}$ & $\begin{array}{l}\text { P. M. } \\
\text { H. } \\
\gamma 1 \gamma^{\prime}\end{array}$ & $\begin{array}{l}\text { А. M. } \\
\text { H. } \\
10\end{array}$ & $\begin{array}{l}\text { P. M. } \\
\text { u. } 37^{\prime}\end{array}$ & $\begin{array}{l}\text { A. M. } \\
\text { H. } \\
1034^{\prime}\end{array}$ & $\begin{array}{l}\text { P. M. } \\
\text { H. } \\
657^{\prime}\end{array}$ \\
\hline February, & 109 & 611 & 956 & 740 & 102 & 656 \\
\hline March, & 1019 & 78 & 101 & $\begin{array}{ll}9 & 9\end{array}$ & 1010 & 88 \\
\hline Aprii, & 858 & 835 & 94 & 817 & $9 \quad 1$ & 826 \\
\hline May, & 921 & 826 & 97 & 854 & 914 & 840 \\
\hline Jume, & 927 & 82 & 847 & 847 & 97 & 8 24. \\
\hline July, & 851 & 836 & 859 & 845 & 855 & 849 \\
\hline August, & 851 & 813 & 98 & 825 & 90 & 819 \\
\hline September, & 844 & 839 & 90 & 757 & 8. 52 & 818 \\
\hline October, & 946 & 654 & 94 & 642 & 925 & 648 \\
\hline November, & 956 & 721 & 923 & 80 & 939 & 741 \\
\hline December, & 1015 & 545 & 937 & 645 & 956 & 615 \\
\hline
\end{tabular}

The following are the results for the six winter months, from October to March inclusive, and for the six summer months, from April to September inclusive :

Six Summer months, Six Winter months,

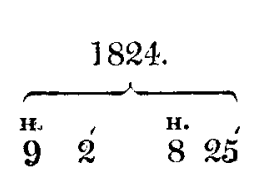

$1012 \quad 6 \quad 49$

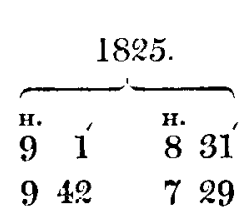

Mean of 1824 \& 1825.

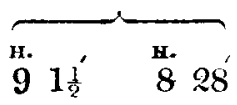

$95 \%$ 7 9

III. On the relation between the Mean Temperature of the 24 Hours and that of any single Hour, or any similar Pair of Hours. $\mathscr{G e}$.

It was long the practice of meteorologists to observe the thermometer three times a-day, on the supposition that the mean of these three observations gave the mean temperature of the 24 hours. Observations of this kind are still continued in many 
378 Dr BREwster on the Register of the Thermomieter kept

parts of Europe. To the following short Table of some of these, I have added the deviations from the mean temperature, as computed from the results of the preceding Tables :

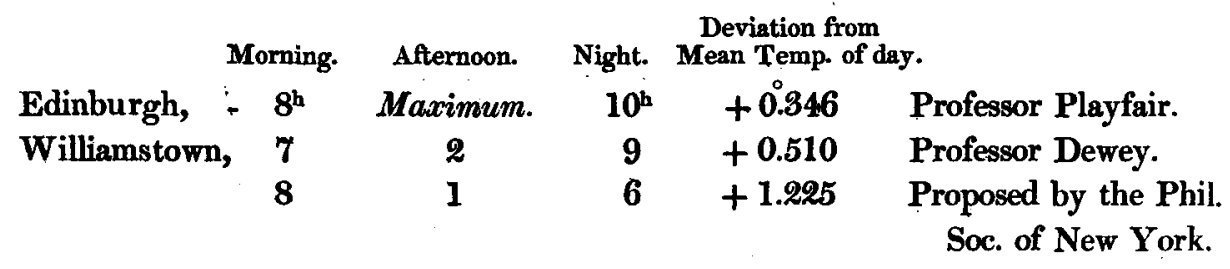

As three daily observations are not convenient for many meteorologists, who are engaged in professional pursuits, it became desirable to select those two hours, the mean of whose temperatures approached nearest to that of the whole day. The following times have been used in this country, and many of them give results that differ very considerably from the mean temperature of the 24 hours :

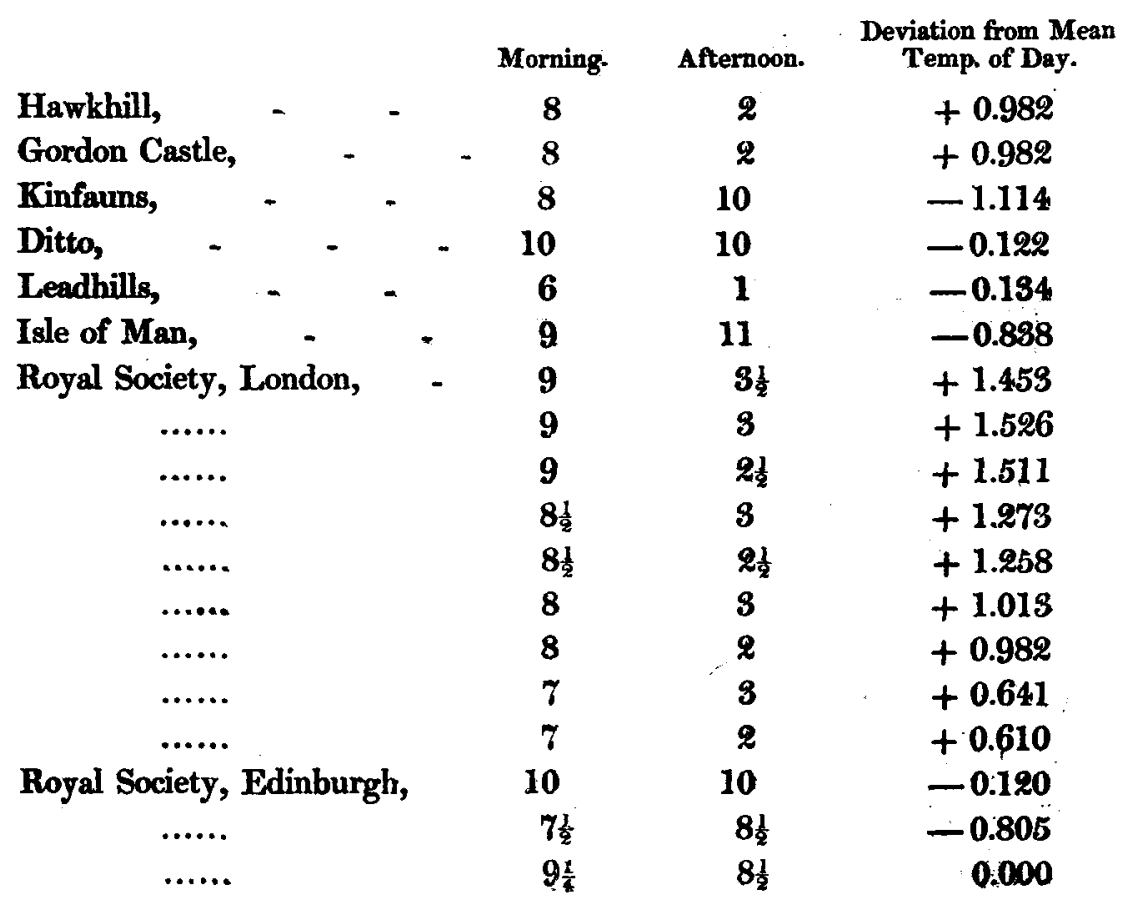


at Leith Fort every Hour of the Day in 1824 and 1825. 379

I have given these examples principally with the view of shewing the application of the results of the hourly register, and not with the design of contrasting the hours employed by different observers ; for it yet remains to be determined how far the form and dimensions of the daily curve, as determined for Leith, are applicable to places in different latitudes, and situated at different heights above the sea. At Paris, for example, the mean temperature of the day occurs before 9 o'clock in the morning; and at Tweedsmuir* in Scotland, 1300 feet above the sea, it happens before $7 \frac{1 \mathrm{~h}}{2}$ A.M. ; but it must be remarked, that the observations at 9 o'clock in the one case, and at $7 \frac{1 \mathrm{~h}}{8}$ in the other, are compared with a calculated mean temperature, and not with the mean temperature of the whole 24 hours $\dagger$.

It is curious to remark, that, with the exception of the hours of 10 А. .., and 10 P. M., no similar pair of hours has been used by meteorologists. The following Table will shew how nearly at Leith the mean of every similar pair of hours approaches to the mean temperature of the day.

* At Salen, Massachussets, where a very accurate register has been kept by Dr Holyoke for twenty-six years, the morning mean temperature always oocurs before 8 o'clock in the morning.

$†$ According to a very accurate register kept by Mr FairLie, schoolmaster of this parish, the results for 1825 are,

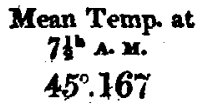

$45^{\circ} .16 i$
Mean Temp. at
818 p. 28.
$43^{\circ}, 825$

Mean Temp. deduced

from these.

$44^{\circ}, 494$ 
380 Dr BREw STER on the Register of the Thermometer kept

TABLE, showing the Deviations of the Mean Temperature of every similar Pairof Hours from that of the Day.

\begin{tabular}{|c|c|c|c|c|}
\hline \multicolumn{2}{|c|}{ Hours. } & 1824. & 1825. & Mean. \\
\hline 5 А.м.... & 5 P.M. & -0.193 & -0.073 & -0.133 \\
\hline 6 & 6 & -0.398 & -0.187 & -0.292 \\
\hline 7 & 7 & -0.448 & -0.256 & - 0.352 \\
\hline ... & 8 & -0.478 & -0.401 & -0.440 \\
\hline 9 & 9 & -0.298 & -0.350 & -0.324 \\
\hline 10 & 10 & -0.148 & -0.096 & -0.122 \\
\hline 11 & 11 & $+0.11 \gamma$ & +0.105 & +0.111 \\
\hline 12 & 12 & +0.359 & +0.286 & +0.319 \\
\hline ... & 1 & +0.447 & +0.301 & +0.374 \\
\hline 2 & 2 & +0.507 & +0.364 & +0.435 \\
\hline ... & 3 & +0.447 & +0.242 & +0.345 \\
\hline 4 & 4 & +0.092 & +0.065 & +0.079 \\
\hline
\end{tabular}

From this Table it follows,

1. That of all the similar pair of hours, the mean of $4^{\mathrm{h}}$ and $4^{\mathrm{h}}$ approaches nearer to the mean temperature of the day than any other pair.

2. That the deviation of any pair is less than half a degree of Fahrenheit's scale.

3. That the mean temperature of the pairs from $5^{\mathrm{h}}$ to $11^{\mathrm{h}}$ are less than the mean temperature of the day; and that the mean temperature of the pairs from $11^{\mathrm{h}}$ to $5^{\mathrm{h}}$ exceed the mean temperature of the day *.

* It now became interesting to compare with these results those deduced from Mr Coldstream's hourly register for one day in each month of the year, and also those obtained by Professor DEwey at Williamstown in North America. 
at Leith Fort every Hour of the Day in 1824 and 1825. 381

In some instances, meteorological registers have been kept, in which the thermometer has been observed only once a-day. These registers may now be rendered useful, by means of the

Results deduced from Mr CoLDstreas's Observations in 1822 and 1823.

\begin{tabular}{|c|c|c|}
\hline Hours. & & $\begin{array}{l}\text { Deviations from the } \\
\text { Mean Temp. of the day. }\end{array}$ \\
\hline 5 and & 5 & +0.005 \\
\hline $6 \ldots$ & 6 & -0.445 \\
\hline $7 \ldots$ & 7 & -0.574 \\
\hline $8 \ldots$ & 8 & -0.580 \\
\hline $9 \ldots$ & 9 & -0.674 \\
\hline $10 \ldots$ & 10 & -0.207 \\
\hline $11 \ldots$ & 11 & -0.170 \\
\hline $12 \ldots 1$ & 12 & -0.106 \\
\hline $1 \ldots$ & 1 & +0.385 \\
\hline $2 \ldots$ & 2 & +0.385 \\
\hline $3 \ldots$ & 3 & +0.840 \\
\hline $4 \ldots$ & 4 & +1.018 \\
\hline
\end{tabular}

The law of the deviations in this table is very regular, particularly when we con sider that the observations were made only on twelve days in the year.

Results deduced from Professor DEWEY's Obserzations.

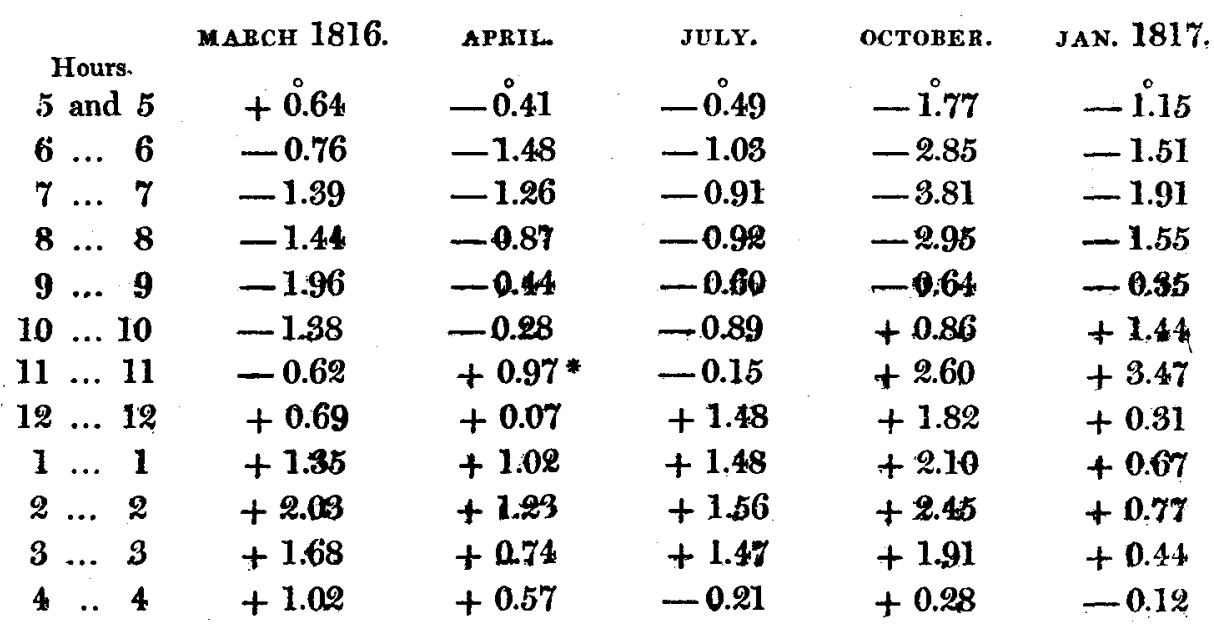

- There is an exror in Profeseor Dewey's mean of 11 P. M.: it should be 34.92, in place of 39.92. 
382 Dr BREwSTER on the Register of the Thermometer kept

following Table, which shews the relation between the mean temperature of each hour and that of the whole day :

\begin{tabular}{|c|c|c|c|}
\hline Hour. & 1824. & 1825. & $\begin{array}{c}\text { Mean of } \\
1824 \& \text { 1825. }\end{array}$ \\
\hline 1 А. M. & -1.97 & -2.296 & -2.133 \\
\hline 2 & -2.19 & -2.478 & -2.334 \\
\hline 3 & -2.41 & -2.746 & -2.578 \\
\hline 4 & -2.66 & -2.975 & -2.818 \\
\hline 5 & -2.77 & -2.976 & -2.873 \\
\hline 6 & -2.59 & -2.637 & -2.613 \\
\hline$\gamma$ & -1.95 & -2.017 & -1.983 \\
\hline 8 & -1.27 & -1.206 & -1.238 \\
\hline 9 & -0.18 & -0.244 & -0.212 \\
\hline 10 & +0.65 & +0.840 & +0.745 \\
\hline 11 & +1.62 & +1.747 & +1.683 \\
\hline 12 & +2.50 & +2.520 & +2.510 \\
\hline 1 P. M. & +2.86 & +2.904 & +2.882 \\
\hline $\boldsymbol{2}$ & +3.20 & +3.206 & +3.203 \\
\hline 3 & +3.30 & +3.230 & +3.265 \\
\hline 4 & +2.84 & +3.105 & +2.972 \\
\hline 5 & +2.38 & +2.830 & +2.605 \\
\hline 6 & +1.79 & +2.264 & +2.027 \\
\hline 7 & +1.05 & +1.505 & +1.277 \\
\hline 8 & +0.31 & +0.404 & +0.357 \\
\hline 9 & -0.42 & -0.456 & -0.438 \\
\hline 10 & -0.95 & -1.031 & -0.990 \\
\hline 11 & -1.39 & -1.537 & -1.463 \\
\hline 12 & -1.80 & -1.937 & -1.868 \\
\hline
\end{tabular}

From this table, it appears, that the mean annual temperature of any hour of the day never differs more than $3^{\circ} \frac{1}{5}$ from the mean temperature of the day for the whole year. It deserves also to be noticed, that the deviations in the year 1825 are uniformly greater than those in 1824, which no doubt arises from the former having been a much warmer year than the latter.

In order to obtain the mean temperature of the year from a register which contains observations made only once every day, we have only to correct the mean temperature which the regis- 
at Leith Fort every Hour of the Day in 1824 and 1825. 383

ter gives, by applying, according to its sign, the correction opposite to the given hour. In place of taking the mean of the two years, it might be preferable to take the results for 1824 in cold years, and those for 1825 in warm years.

Before concluding this part of the subject, it may be interesting to ascertain, from the preceding results, the relation between the mean temperature of the day, and the results obtained from the hours used at Paris, Halle, and Abo, where the thermometer is observed more than three times :

\begin{tabular}{lccccccc}
\multicolumn{9}{c}{ Hours used: } \\
& Morning. & Noon. & Afternoon. & \multicolumn{2}{c}{ Evening. } & $\begin{array}{c}\text { Deviation from the } \\
\text { Mean Temp. }\end{array}$ \\
Paris *, & - & 9 & 12 & 3 & 9 & & +1.282 \\
Halle, & - & 8 & 12 & 2 & 6 & 10 & +1.103 \\
Abo, & - & 8 & 11 & 2 & 5 & 10 & +1.053
\end{tabular}

These deviations are very great, and shew how little is gained by multiplying observations, as in the preceding journals. Any two pair of similar hours would have given deviations less than one-third of those in the preceding table. Indeed, it is obvious, that any number of observations made during the day, can never give a correct mean, without corresponding observations made late at night and early in the morning. In the register at Paris, Halle, and Abo, it would require the addition of the minimum to obtain the proper mean, as appears from the following 'Table :

$\begin{array}{lcccclcc} & & \text { Morning. } & \text { Noon. } & \text { Afternoon. } & \text { Evening. } & \begin{array}{c}\text { Deviation from the } \\ \text { Mean Temp. }\end{array} \\ \text { Paris, Minimum, } & 9 & 12 & \mathbf{3} & 9 & & +0.451 \\ \text { Halle, Minimum, } & 8 & 12 & 2 & 6 & 10 & +0.441 \\ \text { Abo, Minimum, } & 8 & 11 & 2 & 5 & 10 & +0.399\end{array}$

* The hours of 9 and 9 being nearly those that give the mean temperature of the day, it is obvious, that the mean of 12 and 3, must give a result considerably above the mean temperature of the day, and consequently, that the mean of all the four observations must err considerably in excess.

VOL. X. P.II, 
384. Dr BREw STER on the Register of the Thermometer kept

Even with the addition of the minimum, it appears that the mean temperature of these hours errs in excess.

\section{On the average Daily Range for each Month.}

In a climate so variable as that of Scotland, the daily range of the thermometer is often very great, both in winter and in summer; but the average daily range which we propose now to notice, is the measure of the daily change of temperature for each month, and will of course bear some relation to the sun's declination, as appears from the following Table:

TABLE, showing the average Daily Kange of Temperature for each Month, and for the zehole Year.

\begin{tabular}{|c|c|c|c|c|c|c|c|c|c|}
\hline \multirow[b]{2}{*}{ January, } & \multicolumn{3}{|c|}{1824.} & \multicolumn{3}{|c|}{1825.} & \multicolumn{3}{|c|}{$\begin{array}{c}\text { Mean of } \\
1824 \& 1825 *\end{array}$} \\
\hline & $\begin{array}{l}\text { Hour of } \\
\text { Min. } \\
\text { H. } \\
\mathbf{5}\end{array}$ & $\begin{array}{l}\text { Hour of } \\
\text { Max. } \\
\mathbf{H .} \\
\mathbf{3}\end{array}$ & $\begin{array}{c}\begin{array}{c}\text { Daily } \\
\text { Range. }\end{array} \\
\text { 3.11 }\end{array}$ & $\begin{array}{c}\text { Hour of } \\
\text { Min. } \\
\text { F. } \\
6\end{array}$ & $\begin{array}{c}\text { Hour of } \\
\text { Max. } \\
\mathbf{H .} \\
\mathbf{2}\end{array}$ & $\begin{array}{c}\text { Daily } \\
\text { Range. } \\
2.258\end{array}$ & $\begin{array}{c}\text { Hour of } \\
\text { Min. } \\
\mathbf{H} . \\
\mathbf{6}\end{array}$ & $\begin{array}{c}\text { Hour of } \\
\text { Max. } \\
\text { H. } \\
3\end{array}$ & $\begin{array}{c}\text { Daily } \\
\text { Range. } \\
\text { 2.662 }\end{array}$ \\
\hline February, & 8 & $1 \frac{1}{2}$ & 3.68 & 6 & 3 & 3.910 & 6 & 3 & 3.570 \\
\hline March, & 6 & 3 & 5.45 & 5 & 4 & 7.209 & 6 & 3 & 6.152 \\
\hline April, & 5 & 3 & 10.3 & 5 & 3 & 10.958 & 5 & 3 & 10.629 \\
\hline May, & 4 & 3 & 10.0 & 4 & 5 & 7.484 & 4 & 4 & 8.577 \\
\hline June, & $4 \frac{1}{9}$ & 3 & 8.1 & 4 & 3 & 8.558 & 4 & 3 & 8.263 \\
\hline July, & 4 & 4 & 8.7 & 4 & 4 & 10.404 & 4 & 5 & 9.673 \\
\hline August, & 4 & 4 & 7.5 & 5 & $5 \frac{1}{2}$ & 7.822 & 4 & 4 & 7.591 \\
\hline September, & 4 & 3 & 7.6 & 5 & 2 & 8.573 & 5 & 2 & 8.041 \\
\hline October, & 6 & $1 \frac{1}{2}$ & 5.1 & 4 & 2 & 4.661 & 6 & 2 & 4.876 \\
\hline November, & 12 & $2 \frac{1}{2}$ & 4.4 & 2 & 3 & 4.008 & 2 & 3 & 4.154 \\
\hline December, & $7 \frac{1}{2}$ & 1 & 2.4 & 12 & 2 & $2.67 \gamma$ & 5 & $\mathscr{2}$ & 2.308 \\
\hline Whole year & $x, 5$ & 3 & 6.07 & 5 & 3 & $6^{\circ} .06$ & 5 & 3 & $6^{\circ} .138$ \\
\hline
\end{tabular}

- This column is computed from Table VI. and is not the mean of the two preceding columns. 
at Leith Fort every Hour of the Day in 1824 and 1825. 385

From the general character of the year 1825, these results, as might have been expected, present greater uniformity in that year than they do in 1824, or even in the mean of the two years. The mean range is nearly at its maximum about the winter solstice, and gradually increases till April, when it reaches its maximum. It then declines, and again rises to a second maximum in July, after which it gradually diminishes till the end of the season. The mean range for the year is $6^{\circ} .065$, and does not vary above the 100th part of a degree in 1824 and 1825 .

V. On the Parabolic form of the different branches of the Mean annual Daily Curve.

Before concluding this Report, I was desirous of ascertaining if the different branches of the daily curve had a resemblance to any known curve. Their similarity to the parabola is very obvious, from Fig. 2. of Plate XIV. where they are distinctly projected ; and I therefore calculated the following Table, upon the supposition that $\mathrm{AB}, \mathrm{BC}, \mathrm{CD}$, and $\mathrm{DE}$, were parabolic branches of the following dimensions :

$\begin{array}{lll}\text { Branch AB, } & \begin{array}{l}\text { Ordinate, } \\ \text { Abscissa, }\end{array} & \begin{array}{l}\mathbf{A H}=513 \\ \text { BH }=172 \text { or } 2^{\circ} .872\end{array} \\ \text { Branch BC, } & \begin{array}{l}\text { Ordinate, } \\ \text { Abscissa, }\end{array} & \mathbf{C H}=253 \\ & \mathbf{B H}=172 \text { or } 2^{\circ} .872 \\ \text { Branch CD, } & \begin{array}{l}\text { Ordinate, } \\ \text { Abscissa, }\end{array} & \mathbf{C G}=347 \\ & \mathbf{D G}=196 \text { or } 3^{\circ} .266 \\ \text { Branch DE, } & \begin{array}{l}\text { Ordinate, } \\ \text { Abscissa, }\end{array} & \mathbf{E G}=327 \\ & & \end{array}$

The ordinates $513+253+347+327$ are $=1440^{\prime}=24$ hours; and the abscissa $\mathrm{BH}=2^{\circ} .872$, and $\mathrm{DG}=3^{\circ} .266$, when reduced to the'same scale as that of the ordinates, become $17 \%$ 


\section{Dr BREwster on the Register of the Thermometer kept}

and $196^{\prime}$, as one degree of temperature on the projection is equal to one hour. The abscissæ which represent the temperature were reconverted into degrees.

TABLE, sheroing the Mean Annual Hourly Temperature for 1824 and 1825, as observed, and calculated on the supposition of these being the abscissa of Parabolas.

\begin{tabular}{|c|c|c|c|}
\hline $\begin{array}{l}\text { Hours. } \\
\text { H. }\end{array}$ & Observed Temp. & Calculated. & Difference \\
\hline 8 ' $27^{\prime}$ р. м. & Mean, 48.266 & Mean, 48.266 & 0.000 \\
\hline 9 & 47.829 & 47.904 & +0.075 \\
\hline 10 & 47.276 & 47.315 & +0.039 \\
\hline 11 & 46.803 & 46.806 & +0.003 \\
\hline 12 & 46.398 & 46.374 & -0.024 \\
\hline 1 А. м. & 46.134 & 46.021 & -0.113 \\
\hline 2 & 45.933 & 45.747 & -0.186 \\
\hline $\mathbf{3}$ & 45.689 & 45.551 & -0.138 \\
\hline 4 & 45.449 & 45.433 & -0.016 \\
\hline 5 & Min. 45.394 & Min. 45.394 & 0.000 \\
\hline 6 & 45.653 & 45.555 & -0.098 \\
\hline 7 & 46.283 & 46.039 & -0.244 \\
\hline 8 & 47.029 & 46.845 & -0.184 \\
\hline 9 & 48.055 & 47.973 & -0.082 \\
\hline 913 & Mean, 48.266 & Mean, 48.266 & 0.000 \\
\hline 10 & 49.012 & 49.091 & +0.079 \\
\hline 11 & 49.050 & 49.969 & +0.019 \\
\hline 12 & 50.777 & 50.653 & -0.124 \\
\hline 1 р. м. & 51.149 & 51.141 & -0.008 \\
\hline 2 & 51.470 & 51.434 & -0.036 \\
\hline 3 & Max. 51.532 & Max. 51.532 & 0.000 \\
\hline 4 & 51.239 & 51.422 & +0.183 \\
\hline 5 & 50.872 & 51.091 & +0.219 \\
\hline 6 & 50.294 & 50.544 & +0.250 \\
\hline 7 & 49.544 & 49.773 & +0.229 \\
\hline 8 & 48.624 & 48.783 & +0.159 \\
\hline 827 & 48.266 & 48.266 & 0.000 \\
\hline
\end{tabular}

The numbers in column 3 . were calculated by the following formula. From the property of the parabola, we have 
at Leith Fort every Hour of the Day in 1824 and 1825. 387

$$
\begin{aligned}
\mathbf{B H}: \mathbf{B} m & =\mathrm{HA}^{2}: m n^{2} ; \text { and } \\
\mathbf{B} m & =\frac{\mathbf{B H} \times m n^{2}}{\mathrm{HA}^{2}} .
\end{aligned}
$$

But since $\mathrm{AE}$ is the line of mean temperature, $p n$ the depression of the temperature below the mean at the point of time $p$, and $p n=\mathrm{H} m=\mathrm{HB}-\mathrm{B} m$, then, calling $\mu$ the mean temperature, and $y$ the ordinate $m n$, we have the required temperature $T$ at the time $p$, thus :

$$
T=\mu-H B+\frac{H B \times y^{2}}{\mathbf{H A}^{2}}
$$

or if $m$ is the minimum temperature of the daily curve, then, at the point of time $p$, we have

$$
\mathbf{T}=m+\frac{\mathbf{H B} \times y^{2}}{\mathbf{H A}^{2}} \text {. }
$$

For the semi-parabola $\mathrm{BC}$, the formulæ are as follows :

$$
\begin{gathered}
T=\mu-\mathrm{HB}+\frac{\mathrm{HB} \times y^{2}}{\mathrm{CH}^{2}} ; \text { or } \\
\mathrm{T}=m+\frac{\mathrm{HB} \times y^{2}}{\mathrm{CH}^{2}} .
\end{gathered}
$$

For the semi-parabola $\mathrm{CD}$, in which the required temperatures exceed the mean, we have at any point of time $p$,

$$
\mathbf{T}=\mu+\mathbf{G D}-\frac{\mathbf{G D} \times y^{2}}{\mathbf{C G}^{2}} ;
$$

or calling $M$ the maximum temperature of the daily curve,

$$
\mathbf{T}=\mathbf{M}-\frac{\mathbf{G D} \times y^{2}}{\mathbf{C G}^{2}}
$$

For the semi-parabola DE, we have the following formulæ :

$$
\begin{gathered}
\mathbf{T}=\mu+\mathbf{G D}-\frac{\mathbf{G D} \times y^{2}}{\mathbf{E G}^{2}} ; \text { or } \\
\mathbf{T}=\mathbf{M}-\frac{\mathbf{G D} \times y^{2}}{\mathbf{E G ^ { 2 }}} .
\end{gathered}
$$

Upon comparing the parabolic abscissæ in column 3. with the observed results in col. 2 ., it appears, that the greatest difference 
388 Dr Bhewster on the Register of the Thermometer.

is a quarter of a degree of Fahrenheit, and that the differences are most perceptible in the afternoon branch of the curve, between 4 P. M. and 8 P. M.

We have no hesitation, however, in saying, that the mean of a greater number of years will produce a close approximation to the parabola. In 1824, the afternoon branch is irregular. In 1825, which was a year of uniform character, the afternoon branch becomès more convex, and approaches closely to the pärabolic branch; so that the mean of 1824 and 1825 which we have given in col. 2. of the Table, and contrasted with the parabolic abscissa, partakes of the irregularities of 1824, and thus occasions a flatness in the curve, and consequently the differences observed between $3^{\text {h }}$ P. M. and $8^{\text {h }} 27^{\prime}$ P. M. 


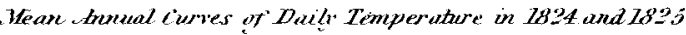

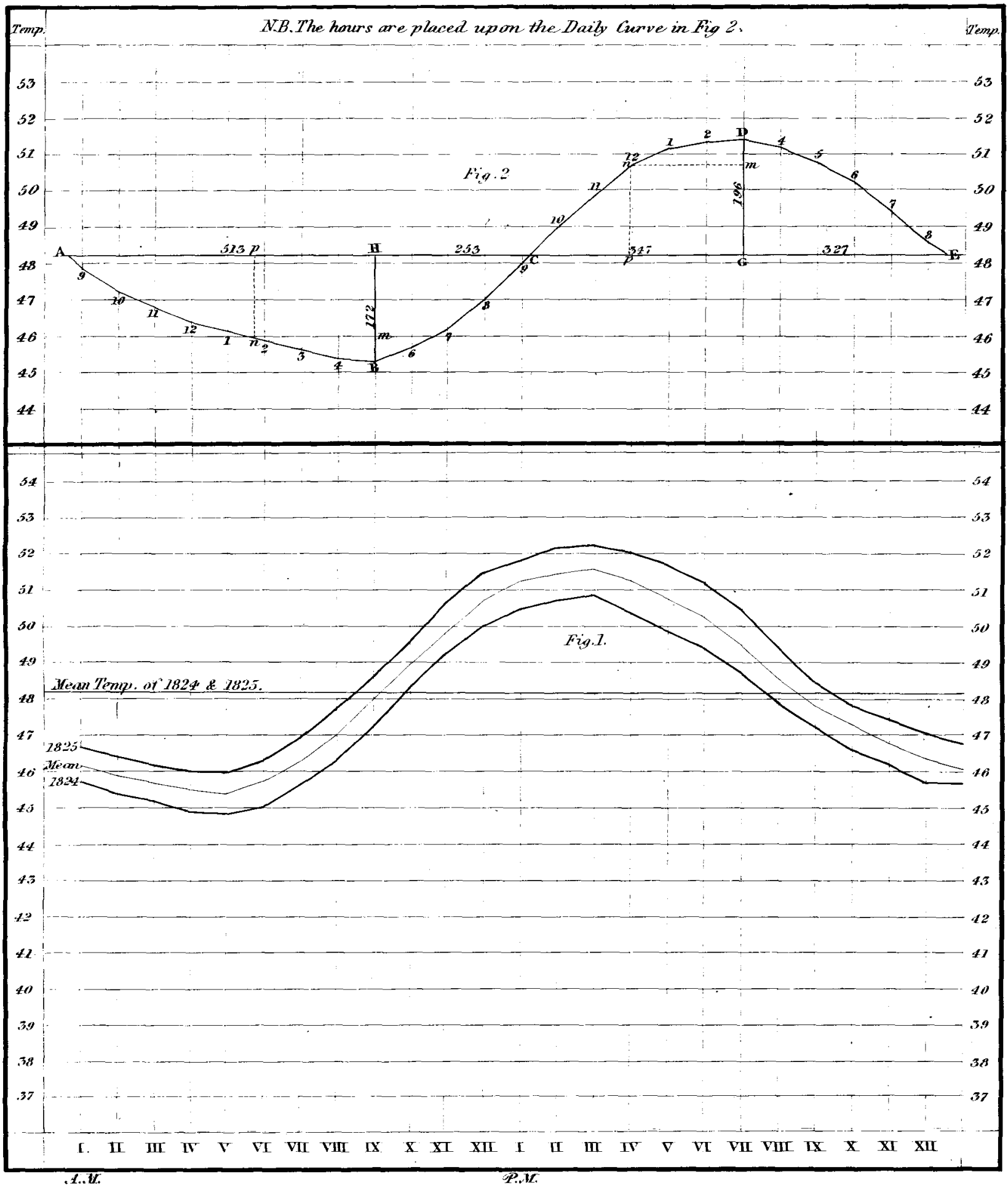




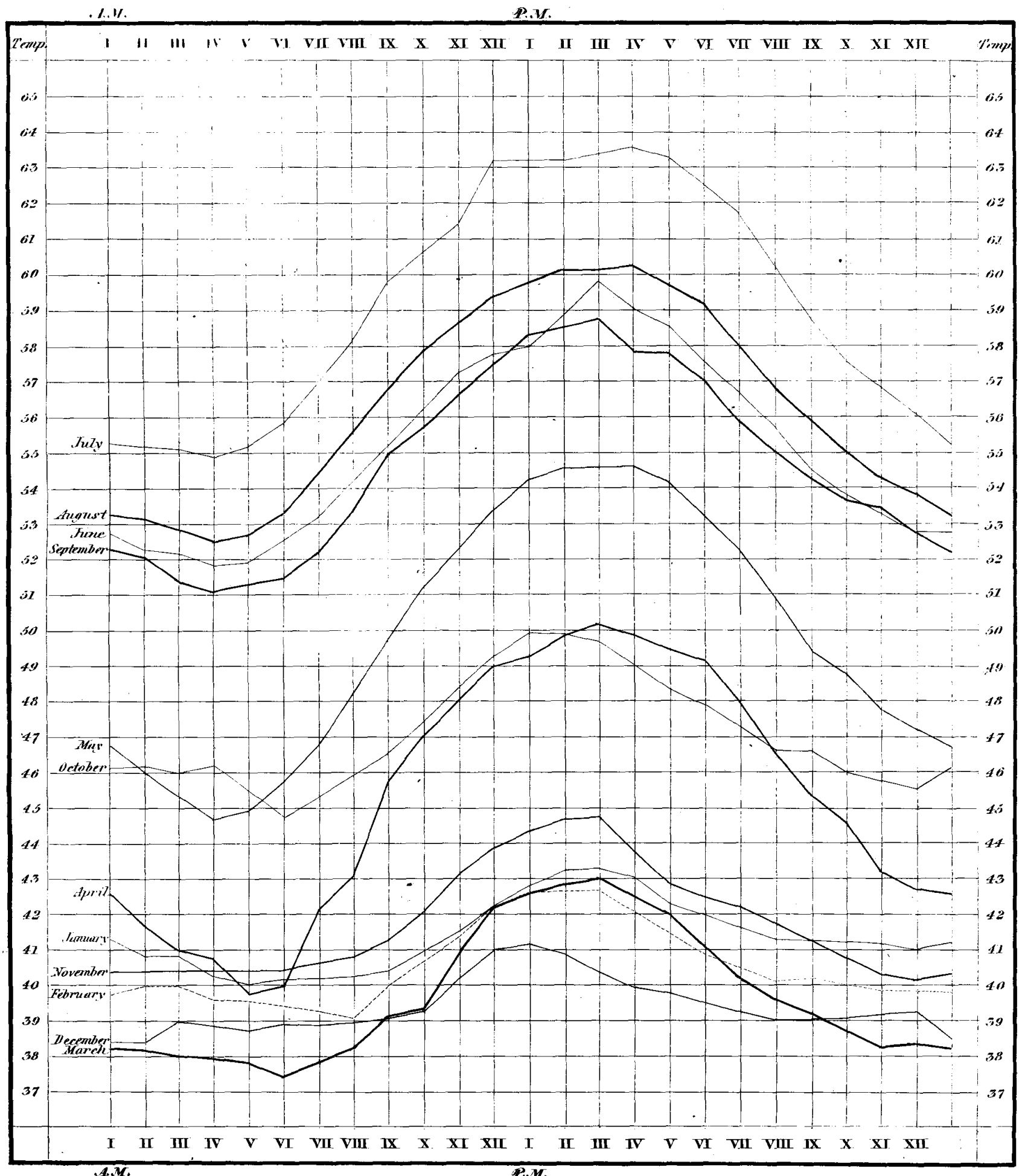


Mean Dait Furve for esch . Werth of 282.5

A.M. P.M.

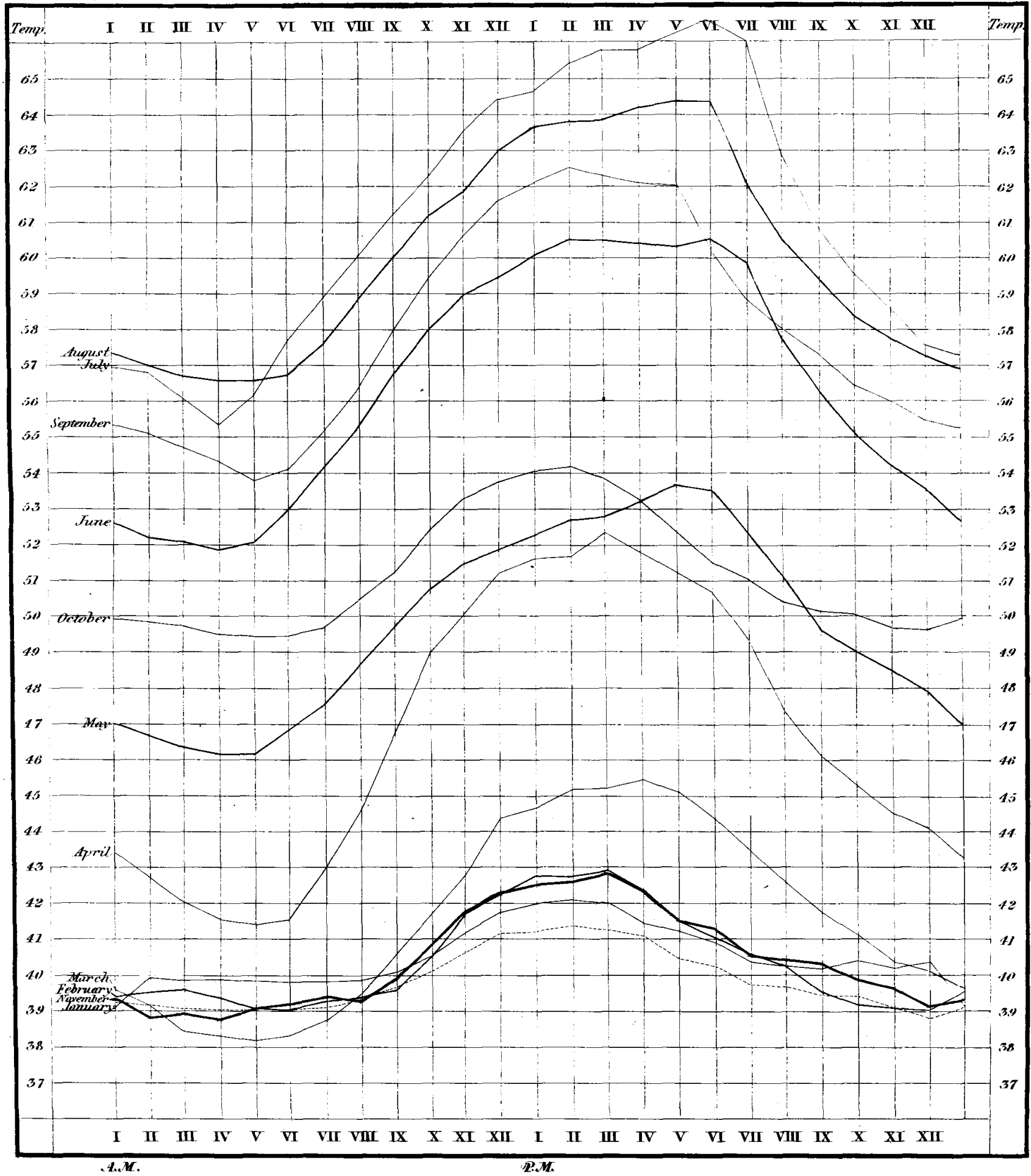




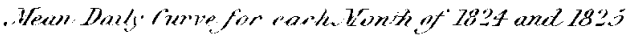

\section{I.M. PR.}

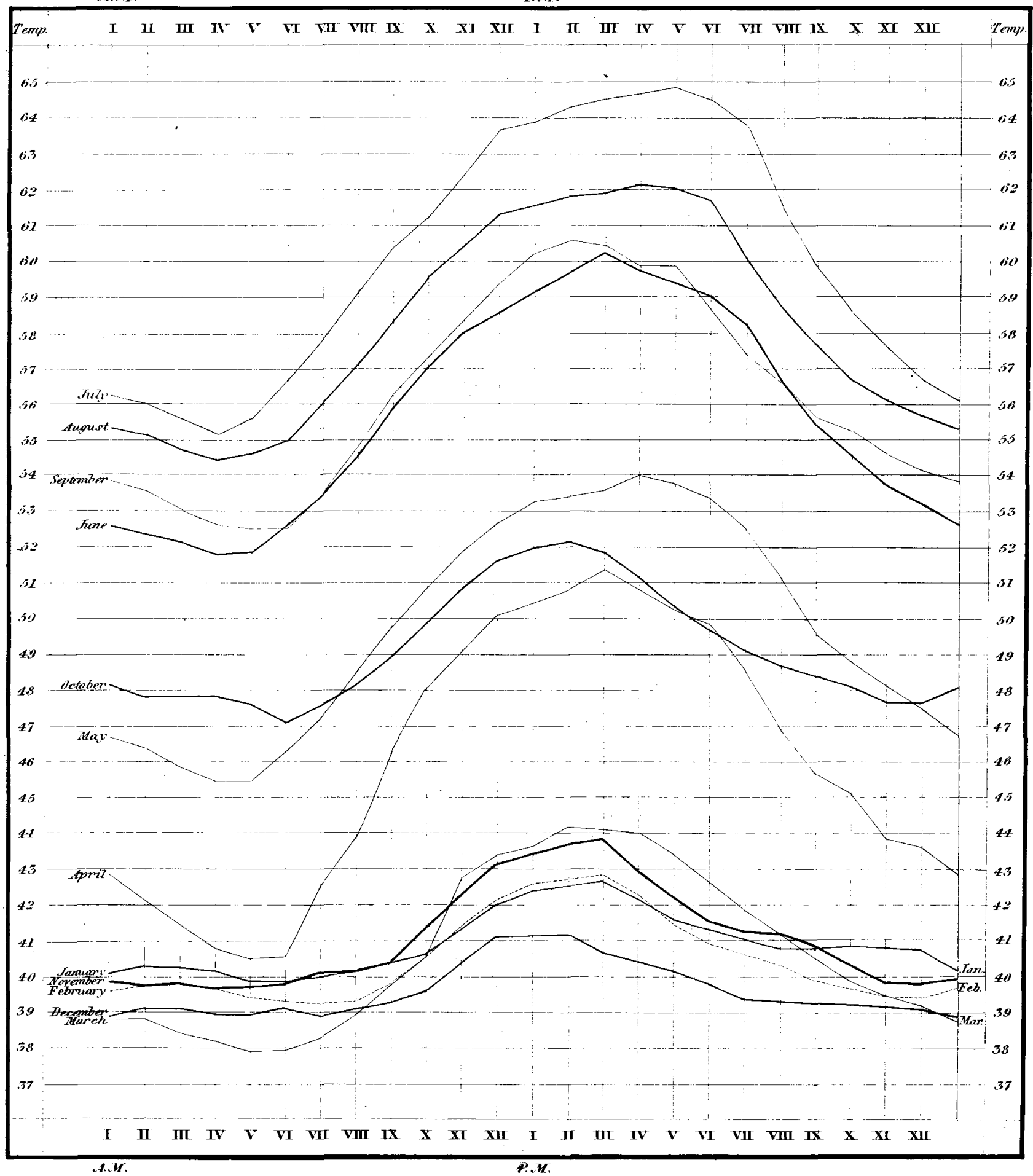




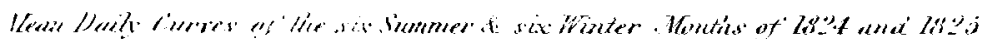

U. K. T.M

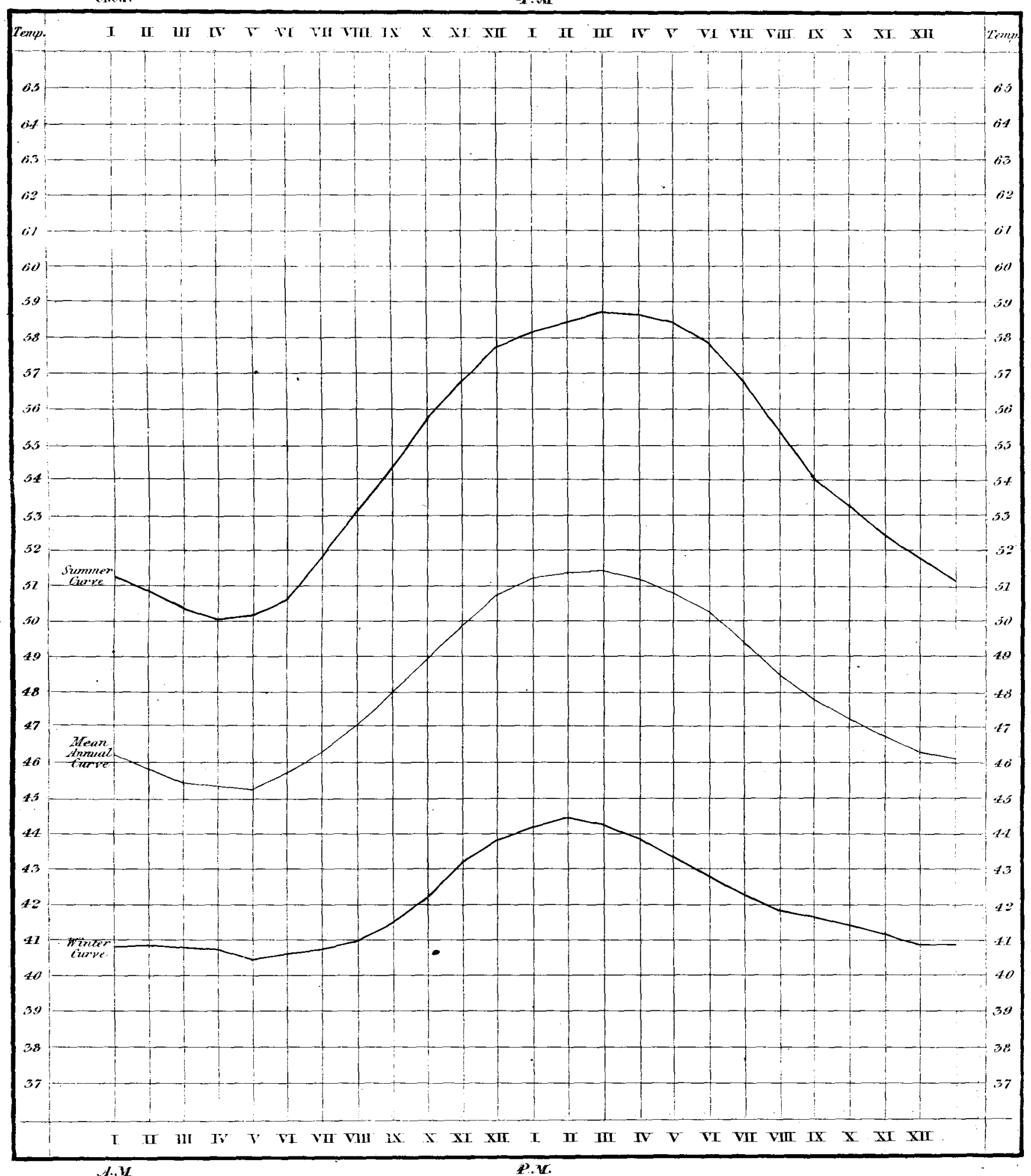

